\title{
Os bichos e os homens: interações socioculturais com a fauna silvestre em uma comunidade amazônica
}

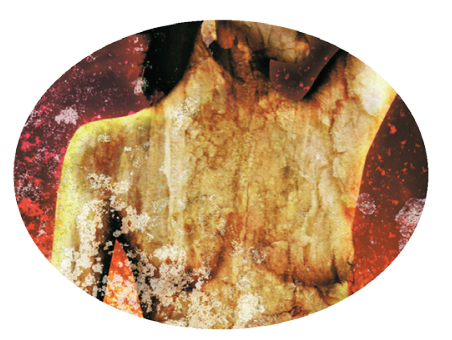

Luciana Raffi Menegaldo* Henrique dos Santos Pereira** Aldenor da Silva Ferreira***

\section{Resumo}

Este artigo descreve as interações culturalmente estabelecidas entre os moradores da comunidade rural Tapiíra, localizada no rio Unini, Parque Nacional do Jaú, Amazônia Central, com o conjunto da fauna silvestre local. Analisa a diversidade dessas interações e a reprodução delas a partir de fatores intergeracionais. Tentamos apreender as interações de fauna do ponto de vista cultural, subjetivo, com intuito de entender a importância da relação mantida entre os homens e os animais, e a forma de socialização dessas interações quando influenciadas por fatores de gênero e geração, objetivando poder contribuir, dessa forma, para o debate acadêmico e político acerca da viabilidade de projetos de manejo de fauna silvestre em Unidades de Conservação de uso sustentável. Os procedimentos metodológicos adotados foram a observação participativa e oficinas de grupos focais. Nessas oficinas foram produzidas free-listings de animais silvestres relacionados a um determinado babitat, além de um denso registro fotográfico e entrevistas semiestruturadas. Os resultados

\footnotetext{
*Doutoranda em Medicina Veterinária pela Universidade Estadual Júlio de Mesquita Filho - Unesp/ Jaboticabal. E-mail: luzoo@hotmail.com

*** Doutor em Ecologia. Coordenador do Programa de Pós-Graduação em Ciências do Ambiente e Sustentabilidade na Amazônia. E-mail: hpereira@ufam.edu.br

**** Doutorando em Ciências Sociais pela Universidade Estadual de Campinas/Unicamp. E-mail: aldenorferreira@yahoo.com.br
} 
demonstram claramente as relações dos moradores da comunidade rural Tapiíra com a fauna silvestre local como contínua fonte geradora de saber tradicional. A socialização desse conhecimento é intermediada por relações de gênero e geração e deve ser preservada, pois é relevante e deve ser utilizado em projetos de conservação da fauna em áreas protegidas. Programas participativos de monitoramento das espécies que valorizem o conhecimento local podem contribuir tanto para a conservação das espécies como para manutenção do modo de vida das comunidades inseridas em Unidades de Conservação.

Palavras-chave: gênero; geração; interação; fauna silvestre; Amazônia.

\begin{abstract}
This article describes the interactions culturally established between the residents of the rural community Tapiira, located on the River Unini, Jau National Park, Central Amazonia, with the local wildlife. The diversity and reproduction of these interactions are analyzed considering intergenerational factors. We try to understand the interactions of fauna from a cultural and subjective standpoint, in order to understand the importance of the relationship maintained between men and animals, and how these interactions socialization factors as influenced by gender and generation, aiming to contribute, this form for the academic and political debate about the viability of projects management of wildlife in conservation units of sustainable use. The methodological procedures used were participant observation and focus group workshops. In these workshops free-listings of wildlife related to a particular habitat, and a dense photographic records and semi-structured interviews were produced. The results clearly demonstrate the relationships of the residents of the rural community Tapiíra with local wildlife as continuous source of traditional knowledge. The socialization of this knowledge is mediated by gender and generational relationships and must be preserved because it is relevant and should be used in projects of wildlife conservation in protected areas. Programs of participatory monitoring of species that value the local knowledge may contribute to the conservation of the species and to maintain the way of life of the communities inhabiting protected areas.
\end{abstract}

Keywords: Gender, Generation; Interaction; Wildlife; Amazon. 


\section{Introdução}

As populações indígenas e não indígenas que habitam o mundo rural na Amazônia mantêm variadas e intensas interações com as espécies da fauna silvestre associadas ao seu modo de vida. De acordo com Pezzuti e Chaves (2009), esses povos baseiam suas atividades socioculturais e de subsistência numa estreita relação de dependência com os recursos naturais do ambiente em que vivem. Dessa maneira, o elemento fauna é parte constitutiva da cultura desses povos. Para esses autores, as interações com a fauna silvestre descritas até agora - envolvendo essas populações, vão desde o conhecimento do comportamento de várias espécies de vespas, pois utilizam seu ninho, pupas e larvas para a preparação de um artefato de pesca, até a criação de pequenos mamíferos nas aldeias como "pets" para as crianças aprenderem seus comportamentos e "criação" de aves coloridas (papagaios e araras), que fornecem suas penas coloridas para vários tipos de adornos e cocares. Para esses autores, esse tipo de cultura ecológica é herdeira direta da cultura indígena e tem em comum a transmissão oral de práticas culturais de uma geração para a outra.

O processo de aprendizagem informal, caracterizado pela transmissão dos saberes pela oralidade e pela imitação nas comunidades tradicionais, é responsável por um arcabouço teórico e prático sobre tudo o que margeia as relações sociais com a fauna silvestre em comunidades tradicionais. De acordo com Pereira et. al. (2007), o conhecimento tradicional não é pré-lógico ou précientífico, ele é baseado em observações contínuas dos fenômenos naturais recorrentes de experimentação, de decisão sobre quais são os ambientes mais adequados e o uso de técnicas mais apropriadas para a caça. Nesse sentido, o conhecimento dos moradores da comunidade Tapiíra acerca dos recursos faunísticos e das técnicas de manejo da fauna são como tecnologias patrimoniais adquiridas no decorrer dos anos e, como tecnologias, devem ser preservadas como patrimônio cultural a ser transmitidos às gerações seguintes e, também, em projetos de conservação de espécies encontradas na área de uso da comunidade.

Os dados a seguir fazem parte dos resultados apresentados no percurso da dissertação de mestrado intitulada "Interações socioculturais da comunidade Tapiíra com a fauna silvestre: relações de gênero e geração”, apresentada junto 
ao Programa de Pós-Graduação em Ciências do Ambiente e Sustentabilidade na Amazônia - Universidade Federal do Amazonas (MENEGALDO, 2011). Todos os moradores presentes nas imagens apresentadas neste artigo apresentaram ciência e autorização prévia para tal, conforme projeto protocolado no Comitê de Ética/Ufam. Por se tratar de pesquisa realizada dentro de Unidade de Conservação, o projeto também foi submetido ao Sisbio.

Tentamos demonstrar nesta pesquisa as estratégias de socialização dos conhecimentos e práticas que permeiam as relações ecológicas com a fauna silvestre entre as gerações em uma comunidade amazônica. Como o título sugere, a área de estudo foi a comunidade rural Tapiíra, localizada no rio Unini, baixo rio Negro, município de Barcelos. Uma comunidade de aproximadamente 160 moradores que está inserida no Parque Nacional do Jaú, uma Unidade de Conservação de Proteção Integral. Foram realizadas duas viagens à comunidade: em julho e setembro de 2010, com duração de 20 dias cada uma delas.

O registro fotográfico, entrevistas gravadas, bem como observações minuciosas do cotidiano da comunidade registradas no diário de campo, possibilitaram-nos fazer uma etnografia das interações dos moradores com a fauna silvestre. Para mensurar a similaridade do conhecimento da fauna silvestre entre homens e mulheres, jovens e adultos, foram realizadas oficinas que tinham como objetivo a confecção de free-listings de animas silvestres relacionados a um determinado babitat. Foram formados oito grupos focais (dois de mulheres jovens, dois de mulheres adultas, dois de homens jovens e dois de homens adultos) e oito questões relacionadas ao conhecimento sobre ecologia animal foram apresentadas a esses grupos. O corte de faixa etária (35 anos) foi proposto para que, dessa forma, fosse possível separar os moradores em "nascidos antes da criação do Parque Nacional do Jaú" e "nascidos após da criação do Parque Nacional do Jaú". Por fim, entrevistas foram realizadas no intuito de confirmar as histórias ouvidas na comunidade e para uma melhor descrição das interações de fauna mais importantes e abundantes que surgiram durante as oficinas. Sendo assim, o formulário foi elaborado para a obtenção de respostas abertas, nos quais o entrevistado teve liberdade de formular sua resposta ou contar a sua história. 


\section{As interações com os animais e o habitus}

As populações tradicionais acumulam, através de gerações, um profundo conhecimento sobre o ambiente que as cerca, baseando-se na observação direta dos fenômenos e elementos da natureza e na experimentação empírica do uso dos recursos naturais disponíveis. Esse uso é orientado por uma série de conhecimentos obtidos mediante a relação direta dos membros da comunidade com a natureza e da difusão das diversas informações transmitidas oralmente (e outras formas) entre as gerações.

As estratégias de reprodução da vida social engendradas por esses indivíduos envolvem tanto a transformação de algumas estruturas quanto a permanência de outras num processo dinâmico. Segundo Bourdieu (1983), a dinâmica social, necessariamente marcada pela produção e reprodução das condições de sobrevivência, pode ser focalizada pela geração de estratégias de reprodução. "Longe de ser o produto automático de um processo mecânico, a reprodução da ordem social ocorre somente através das estratégias" (BOURDIEU, 1992: 114). Estas estratégias seriam o produto do senso prático como sentido do jogo, de um jogo social particular, historicamente definido, que se adquire na infância à medida que se participa das atividades sociais. A estratégia surge não como um "ato de livre escolha do indivíduo, mas como um exercício do senso prático de agentes sociais que buscam concretizar suas perspectivas e projetos dentro das condições dadas pelo universo social específico em que vivem". A estratégia se desenvolve a partir de conhecimentos acumulados, transferidos às gerações futuras por uma prática de oralidade e atividades cotidianas. Bourdieu (1983: 105) faz distinção entre a noção de hábito e habitus. Para ele, "o hábito é considerado espontaneamente como repetitivo, mecânico, automático, antes reprodutivo do que produtivo”. Em relação ao habitus, ele afirma:

O habitus, como aquilo que se adquiriu, mas que se encarnou no corpo de forma durável sob forma de disposições permanentes. Esta noção lembra então, de maneira constante, que se refere a algo de histórico, que é ligado à história individual, e que se inscreve num modo de pensamento genético, por oposição a modos de pensamento essencialistas (como a noção de competência 
que encontramos no léxico chomskiano). Aliás, a escolástica designava também com o nome de habitus algo como uma propriedade, um capital. E de fato, o habitus é um capital, que, sendo incorporado, se apresenta com as aparências de algo inato [...] o habitus é algo que possui uma enorme potência geradora. Para resumir, o babitus é um produto dos condicionamentos que tende a reproduzir a lógica objetiva dos condicionamentos, mas introduzindo neles uma transformação; é uma espécie de máquina transformadora que faz com que nós 'reproduzamos' as condições sociais de nossa própria produção, mas de uma maneira relativamente imprevisível, de uma maneira tal que não se pode passar simplesmente e mecanicamente do conhecimento das condições de produção ao conhecimento dos produtos (BOURDIEU, 1983: 105).

O processo de socialização dos indivíduos nas sociedades tradicionais, dentre outras formas, se dá basicamente pela imitação. Na comunidade Tapiíra, é comum a criança acompanhar os pais nas diversas tarefas cotidianas, domésticas ou não. Tirar água da canoa, por exemplo, pode ser a primeira tarefa do menino no sentido de sua iniciação no mundo da pesca. Ele poderá ainda colocar a isca no anzol do pai ou ajudar a remar a canoa. Quanto à caça, ele poderá ajudar a preparar uma armadilha. A menina que acompanha a mãe nas tarefas da casa é socializada para o cuidado dela, do preparo da comida, do plantio de uma horta etc. No processo de socialização são repassadas também as atividades da rotina do trabalho, que geralmente começa às 5 horas da manhã e só termina com o cair da noite; a confecção de alguns instrumentos de trabalho como a malhadeira ou o manuseio de outros, como o anzol, enxada, o terçado, a poronga etc. O processo de socialização perpassa ainda questões de aprendizagem quanto ao conhecimento e extração dos recursos da floresta, das plantas medicinais etc. Sob a ótica durkhemeana, esses acontecimentos são fatos sociais, pois essas práticas estão difusas nas sociedades tradicionais, portanto têm um caráter de generalidade e são exteriores aos indivíduos. São práticas orientadas pela consciência coletiva que exerce pressão sobre os indivíduos no sentido de uma socialização das práticas. O processo de aprendizagem das técnicas de reconhecimento das plantas (dos poderes curativos e mágicos delas), dos hábitos dos animais, dos peixes etc., não se dá 
de maneira formalizada. Contudo, elas são repassadas (socializadas) a partir de um modelo educacional informal que possui características próprias, aspectos ligados fundamentalmente a uma tradição de oralidade desses sujeitos sociais.

No que tange à educação formal, todos os professores da escola moram em Tapiíra e, portanto, estão familiarizados com seu cotidiano, fato esse que contribui para uma ressignificação e reestruturação de saberes, trazendo para a escola formal aspectos do mundo vivido da comunidade. $\mathrm{O}$ desenho abaixo (Figura 1) foi feito por um aluno do 5. ${ }^{\circ}$ ano do Ensino Fundamental, há dois anos. Foi solicitado em sala de aula que se usasse a imaginação para fazer um desenho criativo, de tema livre. Pressupondo que o desenho reflete a percepção do menino, não há surpresa em observar que o desenho simboliza o cotidiano daquela criança.

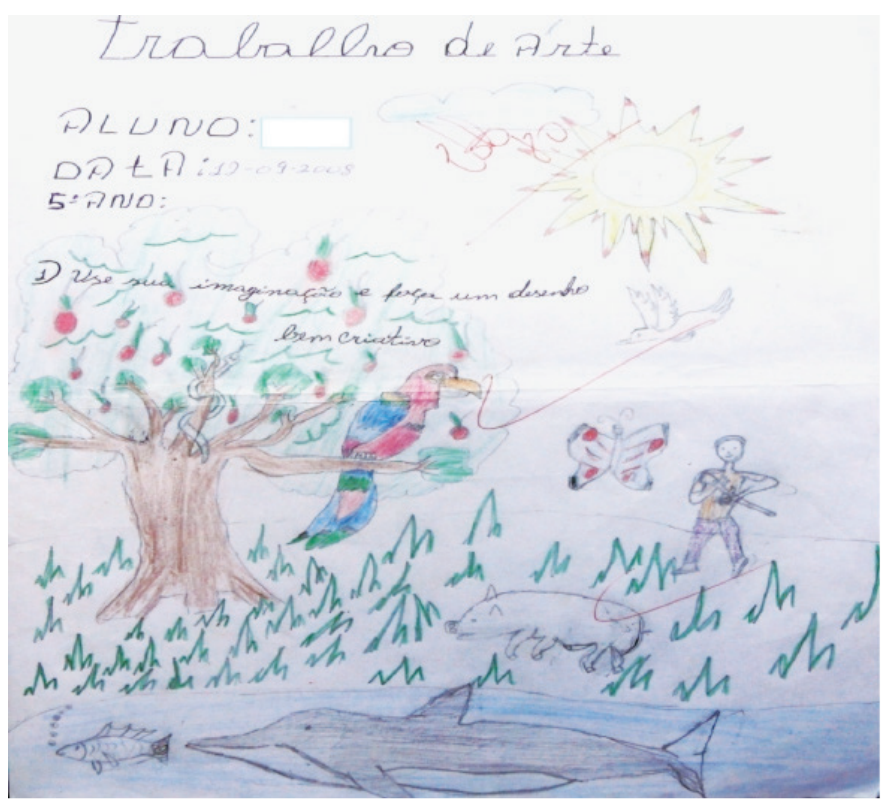

Figura 1 - Desenho de um aluno feito na escola retratando a fauna local.

Fonte: Tiago, 12 anos, morador da comunidade Tapiíra.

As espécies desenhadas ocorrem com frequência em Tapiíra. O porco silvestre é uma carne apreciada pelos moradores e bastante caçada, principalmente nos meses de cheia, os psitacídeos, representados no desenho pela arara-vermelha, são os sons mais presentes durante o dia, tornando-se mais estrondosos e difíceis de não serem notados pela manhã ou no final 
da tarde. A fauna aquática está representada pelo peixe (o alimento mais consumido pela comunidade) e pelo boto-tucuxi desenhado. Em Tapiíra, o boto-vermelho e o boto-tucuxi são observados em abundância, mas quando questionado qual deles estava no desenho, a resposta veio imediatamente: "O boto-tucuxi", e ao responder o porquê da escolha, a resposta foi "ele é mais legal, ele pula mais e não estraga rede". Até o conhecimento da cadeia trófica pode ser identificada no desenho, já que o pequeno peixe está desenhado bem à frente da boca do boto-tucuxi. Borboletas e outras aves são espécies muito abundantes, principalmente nos bancos de areia formados na frente da comunidade durante o período da vazante. Esse local é o preferido pela grande maioria dos meninos para brincar. A prática da caça é facilmente identificada pelo desenho do homem segurando a espingarda, quando questionado quem era o homem do desenho, o aluno respondeu: "Meu pai!".

Embora a educação formal auxilie na formação de conceitos, para as crianças e adolescentes em Tapiíra, como ocorre em grande parte das comunidades rurais da Amazônia, o aprendizado pela imitação e a transmissão dos saberes dos mais velhos pela oralidade tem um papel extremamente importante. Esses saberes não são conhecimentos solidificados, mas vão se reestruturando com a introdução de informações e acontecimentos internos e externos à comunidade.

Com o advento da criação do PNJ, em 1980, a prática da caça sem autorização, para comercialização da carne e/ou do couro, passou a ser exclusivamente exercida para promover a alimentação dos próprios moradores. Embora a Lei de Caça (Lei n. ${ }^{\circ}$ 5.197), que restringe a prática, date de 1967, a realidade geográfica, ambiental e social da região amazônica permitiu uma "tolerância" maior com relação à atividade. A população "jovem” (até 35 anos) da comunidade Tapiíra se desenvolveu junto à realidade da demarcação de áreas protegidas na região. Deve-se lembrar de que, para esses jovens que cresceram dentro de uma nova realidade, a de áreas protegidas, a educação informal era proporcionada pelos mais velhos, senhores(as) que na sua maioria viveram do extrativismo vegetal (seringa, castanha, andiroba etc.) e animal, que, conforme relato dos moradores, estava baseada na exploração de animais tais como: porcos selvagens, jacaré-açu, veados, ariranhas, lontras, pirarucus etc. Esses senhores, com idade superior a 60 anos, pais de moradores jovens (18-35 anos) e que estão presente em uma pequena quantidade na comunidade 
(quatro indivíduos) contam como eles, seus "compadres" e parentes mais velhos (pais, tios, padrinhos) extraíam o couro e a pele dos animais para venda e como escoavam os produtos. A geração de crianças e adolescentes em Tapiíra está convivendo com o fato de o local ser uma área protegida muito mais que seus pais, que "nasceram juntos" com o Parque Nacional do Jaú, mas que foram socializados pelos seus antecessores, que viviam em uma realidade bem distinta, de livre exploração dos recursos naturais, principalmente com relação ao extrativismo. Essa geração de 18-35 anos, que cresceu junto com o PNJ, embora socializada pelos pais, residentes anteriores à criação do parque, tem diluído gradativamente no seu cotidiano a transformação da área em que vive em Unidade de Conservação, e as consequências dessa mudança é a adaptação (ainda que lenta) a essa nova realidade.

Registros na Revista da Associação Comercial da Amaz̧onas (ACA) e nos Relatórios anuais da mesma associação não só demonstram a veracidade das histórias contadas pelos mais velhos, como também mostram que existiam estímulos a essa produção, como se pode ver no Relatório de 1944, onde a ACA pede auxílio à Interventoria Federal para promover o aproveitamento da carne de jacaré que era caçado para a venda do seu couro. O texto traz o problema do desperdício dessa carne, uma vez que ela poderia ser utilizada como fonte de alimento para as populações locais e até mesmo para exportação, se pudessem ser instituídas técnicas de beneficiamento inclusive do óleo, que também era desperdiçado. Apesar de ser um texto da década de quarenta, ele traz consigo a gênese de ideias gerais do manejo de uma espécie e, ainda, de uma preocupação ambiental.

\section{A caça e a pesca}

Primeiramente, serão apresentados os resultados da observação participativa e alguns registros fotográficos que ilustram de maneira singular a interação dos moradores da comunidade com a fauna silvestre. Dentre as diversas interações homem/animal observadas durante a estada em campo, é impossível deixar de evidenciar a relação dos moradores com os animais que são caçados e, também, a maneira intensa de transmitir todo o saber que envolve esse tema às novas gerações.

O hábito da caça na Amazônia advém em grande medida da herança 
cultural indígena e deve ser pensado englobando outros aspectos da dimensão social e cultural. Segundo Moran (1990), a caça na Amazônia consiste numa atividade sazonal relevante, cuja alternativa de alimentação é de extrema importância, além de ser uma atividade de socialização fundamentalmente masculina, mas sem a orientação mercantil (na comunidade pesquisada isso passou a ser uma realidade com o advento do PNJ). Dessa forma, a atividade de caça não pode ser entendida apenas como um processo técnico, ou que esteja somente relacionado ao interesse do comunitário em adquirir alimentos. Apesar de esse interesse ser verdadeiro, a caça não pode ser compreendida exclusivamente por esse fato. Essa atividade liga-se a um processo cultural de produção e socialização do conhecimento sobre a natureza, que obviamente orienta a captura dos animais.

A atividade da caça e da pesca em Tapiíra é precedida de uma estética singular. Essa estética está presente desde a preparação dos utensílios que serão utilizados para a apreensão/abate dos animais e a manutenção deles até o preparo das carnes. Os artefatos de caça e de pesca são confeccionados com muito zelo (Figura 2), inclusive com materiais próprios para o propósito. Se o objetivo é a confecção de um arco, a madeira empregada deve ter maciez e resistência apropriada, da mesma maneira que as lanças. Na comunidade, é natural a socialização dos meninos para os procedimentos de confecção e manutenção dos instrumentos de caça e/ou pesca, bem como comentários públicos pós-caçadas de êxitos e fracassos. A socialização de informações sobre o que ocorre durante uma atividade de caça é intensa. Quando os caçadores chegam aos portos, os meninos, mesmos os mais novos, compartilham muitas dessas informações. Esses "ensinamentos" são transmitidos pela oralidade e pela imitação dos adultos, os mais jovens adquirem a destreza necessária para o bom desempenho na pesca e na caça.

Embora a pesca seja uma atividade bastante conhecida pelas mulheres na Amazônia, e até exercida comercialmente por muitas delas, em Tapiíra a pesca também é uma atividade quase exclusiva dos homens. Duas características colaboram para isso: primeiramente, em Tapiíra não é praticada a pesca comercial, fato que faz com que o esforço da pesca seja pequeno, ou seja, eles pescam apenas para consumo próprio, fazendo com que não seja necessário que as mulheres auxiliem a atividade. $\mathrm{O}$ outro fator que corrobora para que a pesca seja masculina é que a maioria das capturas dos peixes ocorre com 
flechas, uma técnica de pesca tipicamente masculina. Apenas peixes grandes são capturados com redes e a pesca com caniço, embora tenha sido relatada, não foi observada.
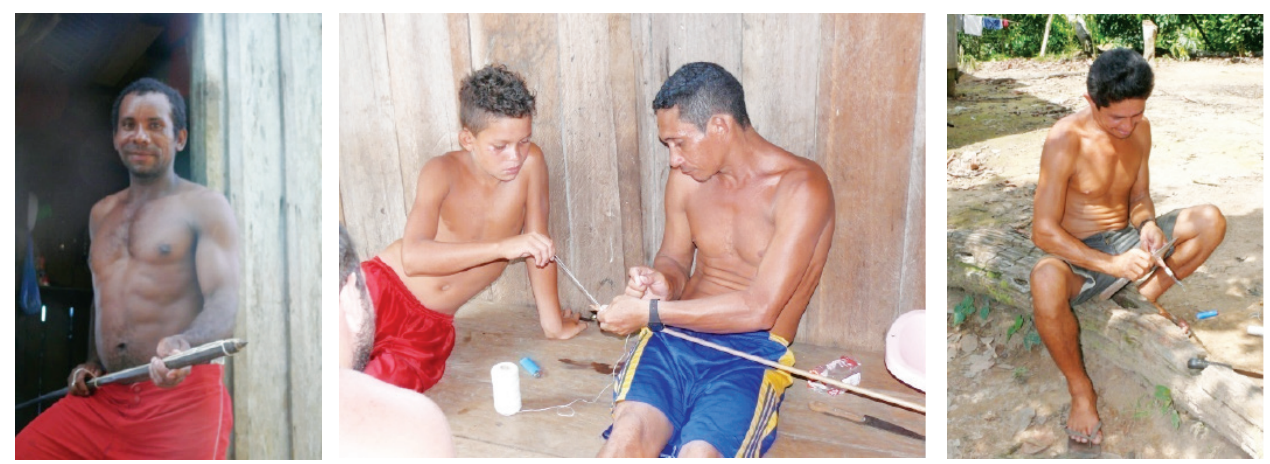

Figura 2 - Da esquerda para a direita: morador apresentando o seu jaticá. Pai ensinando o filho a confeccionar uma lança. Morador confeccionando uma flecha.

Foto: Menegaldo, 2010.

É possível perceber que os animais provenientes da caça são exclusivos ao homem, desde a preparação para a tarefa, como a limpeza das armas e a organização do que será necessário até a limpeza das carcaças nos portos das casas. Durante toda a estada na comunidade, foram observadas oito vezes a chegada de moradores com os animais provenientes das caçadas. Nesse momento, alguns homens se aglomeram no respectivo porto para o auxílio no tratamento das carcaças dos animais. Em todas essas oito ocasiões, apenas uma mulher foi observada nessa atividade, revelando que mesmo esse momento a atividade é masculina. O tratamento das carcaças anuncia o término da caçada êxitosa, e que precisa ser finalizada por eles mesmos ou no máximo por outros homens - nesse caso por aqueles que querem alguma parte ou por homens que têm prestígio ou carisma da comunidade. Em quase todos esses momentos, de chegada de caçadores, o morador mais antigo da comunidade estava presente.

Nas fotos abaixo (Figura 3), observa-se a diferença dos "animais do homem" para os "animais da mulher". Quando os animais presentes nos portos são oriundos da pesca, é observado que a presença da mulher não só é permitida, como desejável. A pirarara, em uma das imagens, é proveniente de uma rede colocada por um morador em um igarapé próximo, que era visitada pelos filhos duas vezes ao dia. Os meninos traziam para casa os peixes capturados na rede e sempre eram recebidos pela mãe. 
Motta-Maués (1999), em seu artigo "Pesca de homem/peixe de mulher(?): repensando gênero na literatura acadêmica sobre comunidades pesqueiras no Brasil", cita Peirano (1975) que, em seu estudo sobre hábitos alimentares da comunidade de pescadores de Icaraí, no Estado do Ceará, mostra a complementaridade entre atividades do homem e da mulher. O primeiro cuidando da "manutenção da família"; a segunda, "da casa e dos filhos".
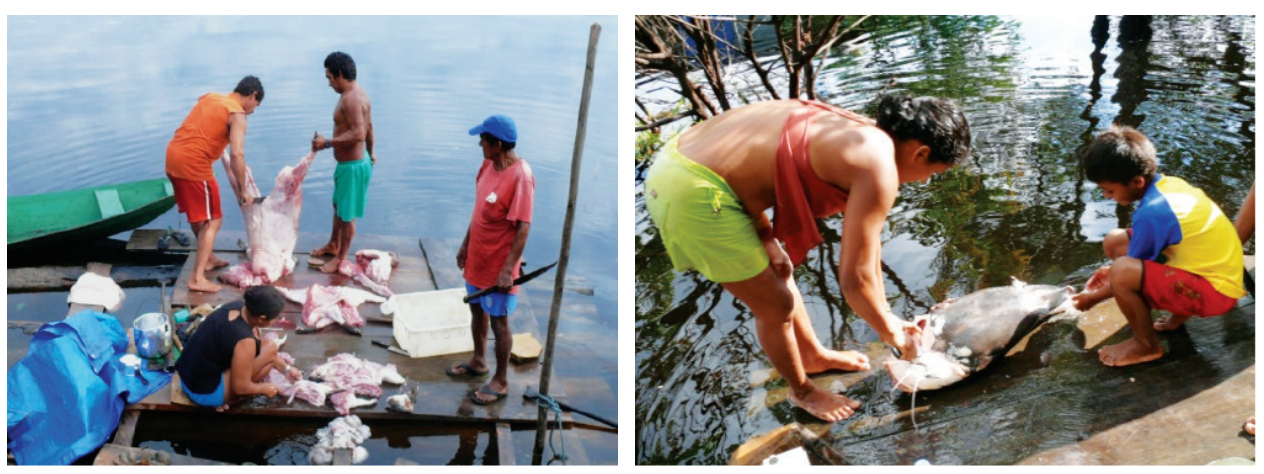

Figura 3 - Da esquerda para a direita: tratamento de carcaças de animais pelos homens oriundos de caça. Tratamento da pirarara pela esposa e filho do morador.

Foto: Menegaldo, 2010.

A pesca e a captura de quelônios pelos moradores da comunidade ocorrem com a utilização do jaticá e do arco e flecha, utensílios que necessitam de destreza para que se obtenha êxito. Essa técnica também é exclusiva dos homens. Como herança cultural amazônica, a captura de quelônios ocorre de forma intensa e preocupante na comunidade. A carne é, segundo eles, saborosa, macia e nutritiva, existindo pequenas variações entre as espécies e preferências particulares. Ovos de quelônios é um alimento bastante apreciado, cuja época é esperada com grande expectativa pelos moradores, inclusive pelos garotos, que se exibem com as quantidades encontradas. Os moradores alegam também que os bichos de casco podem ser armazenados vivos por muito tempo, fato que colabora para que os quelônios sejam capturados em grandes quantidades.

O conhecimento sobre esses animais, bem como dos métodos de captura é específico, diferenciando-se daquele associado à captura de outros animais. $\mathrm{E}$ isso reflete quão rico é o conhecimento das crianças sobre quelônios, 
sobretudo por parte dos meninos (Figura 4). Durante algumas excursões de barco realizadas na área de entorno da comunidade, alguns quelônios foram avistados nas águas e imediatamente identificados pelos moradores. Segundo eles, a identificação da espécie específica é possível pelo modo como colocam a cabeça para fora da água para respirarem, e sua anatomia, que difere de uma espécie para outra. Com os olhos treinados, uma única emergida, mesmo que percebida de relance pelo morador, é suficiente para que os moradores identifiquem a espécie. Eles ainda são capazes de prever depois de quanto tempo e onde o animal irá respirar novamente. Assim, utilizando-se o jaticá ou o arco e flecha, a captura tende ao sucesso.
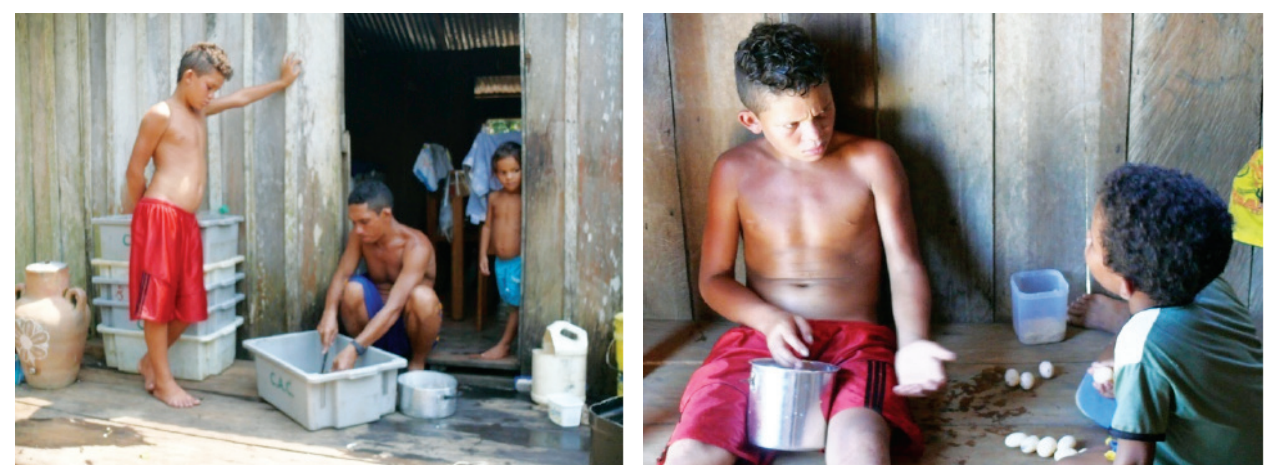

Figura 4 - Da esquerda para a direita: morador tratando um tracajá e filho observando atenciosamente. Contagem de ovos pelos garotos.

Foto: Menegaldo, 2010.

Muito se discute sobre a conservação de quelônios na Amazônia. No rio Unini, não é diferente; mas felizmente, em Tapiíra, são raras as ocorrências de comercialização ilegal de quelônios. Segundo Ferrara et. al. (2010), a preocupação de pesquisadores com a região diz respeito ao intenso consumo de "subsistência" e a intensidade da coleta de ovos. De acordo com os relatos e registros de caça e pesca, a comunidade Tapiíra é "oportunista" no que tange à alimentação. Os alimentos são "escolhidos" de acordo com o seu período de abundância e/ou facilidade de captura: na vazante/seca, os peixes estão mais concentrados, sendo assim capturados com maior frequência; na enchente/ cheia, os animais terrestres estão mais confinados à terra firme, sendo capturados com mais facilidade e menor esforço. Da mesma maneira ocorre com os quelônios. O problema é que nessa época aumenta a oportunidade 
de captura de fêmeas reprodutivamente ativas, o que reduz a taxa de desova das espécies. Todos esses fatores se tornam mais preocupantes se somado à grande quantidade de ovos capturados nas praias, o que, obviamente, acarreta a redução da taxa de nascimento. A comunidade participa de um projeto de conservação que monitora a população de quelônios e foca na educação das crianças e jovens.

\section{O uso medicinal dos animais}

Em Tapiíra a interação com os animais não ocorre apenas com o intuito de alimentação. $\mathrm{O}$ uso de parte de animais para a produção de receitas caseiras é abundante, perdendo apenas para as soluções, xaropes e banhos produzidos a partir de plantas com propriedades medicinais. Todavia, a utilização dessas receitas caseiras é menos comum que no passado. Um dos fatores que contribuiu para a diminuição dessas receitas foi a instalação de um posto de saúde em 1999 com a presença de um agente de saúde fixo. Mesmo com o decrescente uso de remédios caseiros pelos moradores, ainda é possível observar a prática da reserva de algumas substâncias animais nas residências. Quando uma espécie é caçada, os moradores utilizam algumas partes dos animais para a confecção de remédios que são utilizados para a cura de alguma doença ou contusão. Também são utilizados chás para "tirar olho grande", "dar coragem" e cremes são produzidos para hidratação do corpo a partir da banha de algumas espécies, como a banha da tartaruga.

Dentre as diversas "prescrições" reconhecidas pelos moradores, as mais utilizadas são: penas de aves, couros de peixes e répteis ou carapaças que são queimados em pequenos fogareiros. Cada parte de um animal - cada "receita" - é específica para uma doença. Abaixo, a moradora Josineide, 21, relata esse tipo de prática, onde parte de animais são usadas para produzir a "fumaça terapêutica" e, também, sobre um chá para hemorragias:

Usamos o couro do cuiú para fazer chá e tomar. Serve para hemorragia. É um tipo de peixe assim como um boto, a feição de um boto, só que não tem o bico grande. Mas tem aquela serrinha na boca e é preto. É um peixe que a gente come, eu como. O couro dele parece com o da pirarara. Só não a cor. Aí a gente tira só a serrinha e faz o chá. Queima 
a serrilha, aí soca ela, peneira, faz o chá e toma (Josineide, 21, moradora).

Têm vários remédios, eu não lembro muito. Agora, a mamãe sabe muito de remédio caseiro. Eu já vi fazendo, eu tinha um livrinho que era dela, deram para ela, só de remédios caseiros. Uma vez a mamãe usou a banha da onça para curar o Leandro da asma [...]. A gente tira a banha dela, derrete e faz um chá. Primeiro faz uma chá dessa cebola de cabeça, aí põe mel aquela banha dentro, bate bem, e dá para a criança tomar. Ah, mas é horrível. Ela deu para esse meu filho aqui. Ele tava com asma [...] a banha da onça a minha cunhada tinha um pouco (Josineide, 21anos, moradora).

As serpentes em Tapiíra são mortas quando encontradas próximas a casa, no quintal ou na roça, por representarem perigo, mesmo quando não peçonhentas, são abatidas para a produção de óleo a partir da banha do animal. Nesse caso, jiboias e sucuris (chamada na comunidade de sucuriju) podem ser poupadas se forem jovens (não apresentam quantidade de banha suficiente). Na Figura 5, o morador M. exibe uma sucuriju e o local onde foi feito o corte para a retirada da banha. Não há excursões específicas para a captura desses animais para esse fim, geralmente os animais abatidos são, na grande maioria das vezes, encontrados durante outra atividade, ou por acaso no roçado ou em uma pescaria.

A banha do animal (gordura localizada na região do peritônio) é retirada e colocada em um recipiente para ser "apurada" no fogo, derretida, é armazenada em pequenos recipientes. O óleo das sucuris (Figura 5) normalmente é utilizado para a cicatrização de feridas, enquanto a banha de quelônios terrestres (jabuti) é utilizada para desfazer inchaços causados por torções e batidas. Já a banha da tartaruga é muito utilizada para tratar hérnia. Dona F., agente de saúde, explica que o procedimento para a obtenção de óleos de quelônios é o mesmo utilizado nas sucurijus. No caso de torções e hérnias, onde se usa óleo dos quelônios, a pessoa deve passá-lo na região contundida à noite, antes de dormir, e fazer uma pequena massagem. A banha dos animais também pode ser utilizada para fins cosméticos, transformando-se em cremes, sendo utilizada pelas mulheres para a hidratação. A banha batida junto com perfume é utilizada no corpo e na face. Na Figura 5, óleos produzidos a partir da banha dos animais e uma cabeça de queixada de onde será extraída a presa 
que será fervida e o chá tomado para mordida de cobra, também usam o chá como solução tópica para essas mordidas ou mesmo outros ferimentos. Dona F. recomenda o chá do dente do queixada, solução oral, para pneumonia. Ela também conta que já usou a banha de manguari, uma ave semelhante à garça, para inflamação.
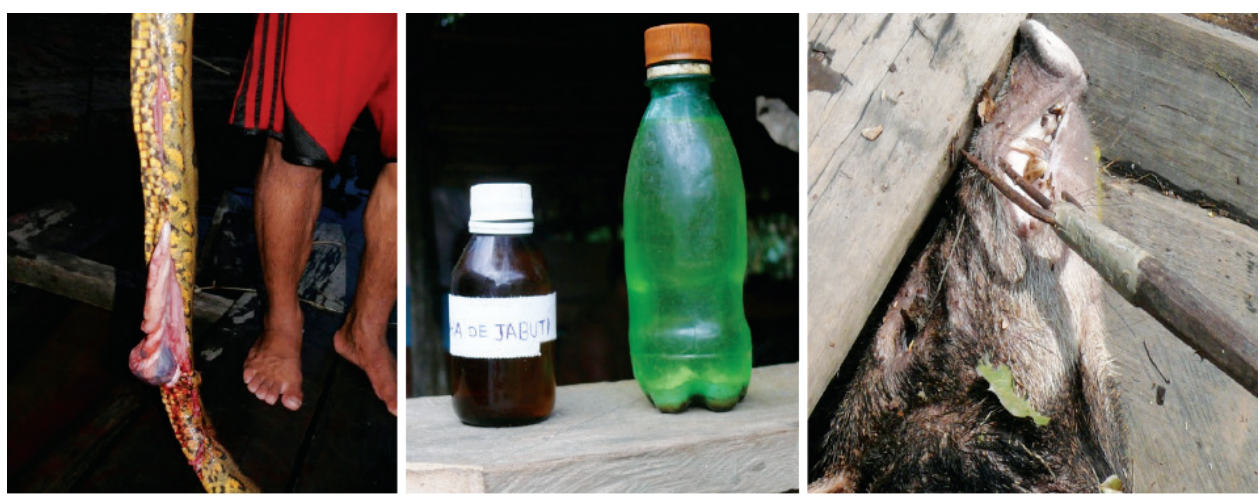

Figura 5 - Da direita para a esquerda. Sucuriju caçada para retirada da banha. Recipientes com óleos de jabuti (frasco escuro) e óleo de sucuriju (frasco verde). Dente de queixada. s Menegaldo, 2010.

Como demonstrado, as interações dos animais com os homens são antigas e ultrapassam o limite do utilitarismo (pelo menos aquela direta, tipicamente comercial). A fauna silvestre está inserida no modo de vida dos moradores daquela região, e o contato com os animais ocorre todo o tempo, seja em casa ou no local de trabalho. A presença dos animais silvestres em Tapiíra é muito mais intensa quando comparada a algumas comunidades do baixo Solimões (MENEGALDO, 2008). Segundo dados da autora, na comunidade Nossa Senhora das Graças, em frente a Manacapuru, o motivo da ausência de animais de caça e outras espécies é, segundo os moradores, o afugentamento causado pelo barulho dos barcos e pela intensa movimentação dos pescadores pelos lagos, perdendo somente para a perda do babitat. Não há dúvida de que a baixa densidade demográfica e a ausência da pesca comercial na região do rio Unini são fatores principais da intensa presença da fauna de maneira tão próxima à área da comunidade. Obviamente, muitos animais não são caçados para consumo alimentar, embora o Sr. T. tenha revelado que papagaios, macacos e preguiças já tenham feito parte da sua dieta, mas como ele mesmo revela: "hoje em dia ninguém aqui precisa comer esses bichos, 
tem outros". Demonstrando uma separação dos animais por categoria, em comestíveis e não comestíveis.

A "coleta" de animais objetivando a criação doméstica para companhia, embora mais intensa nos anos anteriores, ainda ocorre na comunidade e "encanta" os moradores, tanto homens, mulheres e crianças (Figura 6). Para Thomas (2010), três traços particulares distinguem o animal de estimação dos outros animais. O primeiro é que o animal de estimação tem permissão para entrar em casa, a segunda característica distintiva é que esse animal recebia um nome pessoal e individualizado, que o distinguia das outras criaturas e, por fim, esses animais (indivíduos) jamais serviriam de alimento.

Nas relações com animais de "companhia", é mais comum observar o apego a um papagaio ou outro animal silvestre do que propriamente aos cães e gatos. Inclusive, vale ressaltar, que Tapiíra não é uma comunidade com muitos cães e gatos. E esses, quando existem, na sua grande maioria, ficam apenas no quintal, não sendo bem-vindos dentro de casa. Dos três gatos registrados em Tapiíra, apenas um tem acesso ao interior da casa em que vive. Alguns cães, apesar de identificados pelos moradores com "esse aí era do Sr. Fulano" ou "aquele era da outra casa, mas começou a ficar aqui", frequentam toda a comunidade. Esses animais estão muito descuidados, provavelmente pela competição por alimento e pela ausência de cuidados mais específicos, ao contrário do que ocorre com as aves que foram registradas como animais de companhia. Duas moradoras em Tapiíra têm papagaios de estimação, um para cada uma. E o cuidado que essas senhoras têm com os seus papagaios reflete bem isso. Também há na comunidade um macaco-prego, criado como pet e, a grande maioria dos moradores conta histórias de outros animais que já tiveram ou que desejariam ter.

Embora exista esse sentimento por parte dos moradores, de terem os animais para "cuidarem", vale ressaltar que alguns mamíferos, filhotes que eles citaram, são animais que tiveram suas mães caçadas para alimentação. É possível perceber em alguns relatos o pesar dos homens ao virem que mataram fêmeas prenhas ou com filhotes. Um dos fundadores da comunidade demonstra, em muitos relatos, um sentimento de perda quando os animais filhotes trazidos para a comunidade morrem ou vão embora. Essa evasão do animal de volta à floresta ocorre por conta do início da fase reprodutiva, já que, com os níveis hormonais alterados, o animal fica mais propenso a seguir os seus 
instintos de encontrar um parceiro para a procriação. Quando o filhote trazido é macho, também há histórias de que o animal (principalmente primatas), quando chega a essa fase, muda o comportamento, ficando muito agressivo. Esse comportamento, de fuga dos animais (herbívoros) ou agressividade (carnívoros), ocorre por conta do grau de domesticação dos animais.

De acordo com Bowman (1980: 26), há distinção entre domesticação e amansamento. A domesticação inclui o controle da fase reprodutiva, do ciclo de vida e da seleção dos reprodutores, o que o amansamento não faz. $\mathrm{O}$ amansamento é a prática de eliminar o desejo do animal de fugir e possivelmente de treiná-lo para uma função útil. A prática tem de ser repetida novamente em cada animal capturado no meio selvagem. Do que se conhece a respeito dos caracteres de cada espécie é razoável supor que os animais, que podem ser amansados mais facilmente, são os que se reproduzem em cativeiro e, assim, estão aptos a formar a base de um grupo domesticado. Parece, portanto, que as espécies domesticadas já passaram em algum estágio, por um período de amansamento, ou seja, podemos considerar o amansamento como parte do processo de domesticação. Nos animais silvestres "de estimação", criados em Tapiíra, pode-se dizer que se o objetivo do amansamento é a eliminação do desejo de fuga, os pets criados pelos moradores não chegam nem ao estado de amansamento. Essa informação deve ser levada em conta em todo tipo de proposta de manejo de animais silvestres ex-situ ou qualquer tipo de sistema fechado ou semifechado, tendo em vista que nesse tipo de manejo geralmente se faz necessário algum tipo de manipulação dos animais.

Embora o aprendizado sobre a fauna silvestre ocorra pela oralidade de forma intensa, os animais observados no cotidiano pelos moradores, principalmente pelas crianças, enriquecem, e muito, o conhecimento. As imagens abaixo registram espécies comuns (a ariramba e a garça) que vivem próximo à beira do rio, local onde os moradores permanecem parte do dia em diversas atividades, como o banho, o cuidado com a roupa e a louça, o preparo das carnes e dos peixes e onde as crianças, além de auxiliarem nessas atividades, brincam por muito tempo. Todos os animais registrados nas imagens foram antes identificados pelos moradores, inclusive pelos jovens. A maitaca-de-cabeça-roxa e o papagaio fazem parte de bandos que todo fim de tarde fazem "arruaça" nas árvores da comunidade, impondo as suas presenças a todos os moradores. 

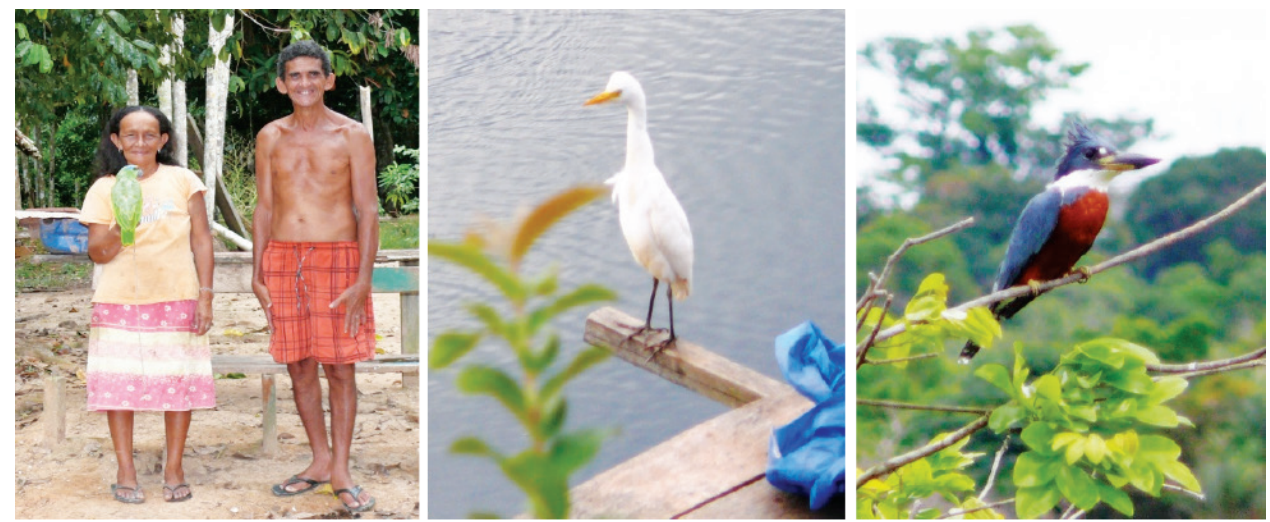

Figura 6 - Dona E. e esposo com seu papagaio. Animais presentes na comunidade: garça e ariramba.

Foto: Menegaldo, 2010.

As pipiras-vermelhas, por exemplo, danificam as frutas dos cajueiros e não existe nenhum tipo de ressentimento em relação a isso. Pelo contrário, um morador explica: "tem uma porção que a gente planta para os bichos, pois aqui era a casa deles antes. Aqui a gente não planta só para a gente, mas para eles também. Daí chega passarinho, tucano, papagaio... tem um tempo que estava ruim de variedade de fruta por aí, não era época, daí os tucanos estavam vindo comer aqui caju". O conhecimento da fauna pelos moradores e que são passados aos filhos e netos, que o registram e o reestruturam (ou não), vem de observações como esta, citada acima, que revela conhecimento sobre os hábitos alimentares dos animais. Outros exemplos vão mais adiante, incorporando até o conhecimento da biologia da espécie, como visto no caso dos quelônios. Todavia, é importante destacamos também que em muitas situações ocorre o ressentimento em relação a alguns animais, como ocorre com os porcos, que atacam roças, as ariranhas e os botos que mexem nas malhadeiras, os gaviões que atacam galinhas etc. Quando isso ocorre, há, sim, certo ressentimento; todavia, na maioria das vezes, efêmero.

\section{Considerações finais}

Foi observado, na maioria das respostas, que a distância entre os grupos iguais (mesmo gênero-geração) é muito pequena, ou seja, a similaridade entre 
as listas é grande. Dos oito dendogramas produzidos, pode-se verificar que em quatro deles (referentes às questões $1,2,5,8$ ), a menor distância entre as respostas (maior similaridade) ocorreu entre os homens adultos. Estes resultados corroboram com as expectativas de que esses grupos (homens adultos 01 e 02) fossem capazes de associar mais espécies e dentre estas muitas não citadas pelos outros grupos, revelando como interagem com a fauna de forma mais intensa e diversificada que as mulheres e os jovens. Em dois dendogramas (referentes às questões 3,7 ), observa-se maior semelhança de resultados dos homens adultos com os homens jovens. Em um dendograma (referente à questão 6), os homens jovens são o grupo de maior similaridade entre si, e em outro dendograma (referente à questão 4), a similaridade é maior entre homens jovens e mulheres adultas). As mulheres também têm espécies que foram citadas apenas por elas, embora em um número menor do que o dos homens. A relação de geração existente entre os homens não é percebida nas mulheres na mesma intensidade.

As relações dos moradores da comunidade rural Tapiíra com a fauna silvestre local é uma contínua fonte geradora de saber tradicional. Como visto, a socialização desse conhecimento é intermediada por relações de gênero e geração e não apenas, mas principalmente pela atividade da caça, que, sendo atividade essencialmente masculina, promove entre os homens maior intimidade com a mata. Esse conhecimento deve ser preservado, pois é relevante e deve ser utilizado em projetos de conservação da fauna em áreas protegidas. Programas participativos de monitoramento das espécies, que sofrem maior pressão de caça, como os quelônios, e que valorizem o conhecimento local, podem contribuir tanto para a conservação das espécies como para a manutenção do modo de vida das comunidades tradicionais inseridas em Unidades de Conservação.

A compreensão da questão de gênero e geração é importante porque se os moradores da reserva devem participar das ações de conservação da fauna silvestre local, é condição sine qua non que sejam compreendidos e levados em conta os seus papéis de homens e mulheres como protagonistas das ações de conservação, pois suas ações/interações revelam estratégias de socialização das práticas de manejo da fauna e, também, as mudanças de comportamento e percepção, que em parte são influenciadas pelas mudanças políticas, como, por exemplo, o recrudescimento das regras internas das áreas protegidas. 
As interações socioculturais entre moradores e a fauna local deverão ser consideradas e valorizadas na elaboração de propostas e ações de manejo das espécies com maior potencial, observando sua viabilidade econômica, social e ecológica, de modo a que se possam alcançar resultados mais sustentáveis. Partindo-se de rotinas já estabelecidas ou de intervenções que introduzam inovações mais adequadas e adaptáveis ao contexto local, poderão ser planejadas estratégias de manejo participativo que resultem em ganhos conservacionistas para as espécies da fauna silvestre local e para a proteção e valorização das práticas culturais estabelecidas entre os moradores do rio Unini de outras Unidades de Conservação da Amazônia.

\section{Referências}

BOURDIEU, P. Questões de Sociologia. Trad.: Jeni Vaitsnan. Rio de Janeiro: Marco Zero, 1983.

BOURDIEU, P. A Economia das Trocas Simbólicas. 3.a ed. São Paulo: Perspetiva, 1992.

BOWMAN, J. C. Animais úteis ao homem. Coleção Temas de Biologia. São Paulo: EPU / Editora da Universidade de São Paulo, 1980, 73 p.

FERRARA, C. R. et. al. Conservação e manejo das tartarugas da Amazônia. Coordenação de Pesquisa em Biologia de Água Doce e Pesca Interior. Manaus: Instituto Nacional de Pesquisas Amazônicas, dezembro de 2010, 61 p.

LIMA, D.; POZZOBON, J. Amazônia socioambiental. Sustentabilidade ecológica e diversidade social. Estudos Avançados, v. 19 (54), 2005.

MENEGALDO, L. R. O etnoconhecimento como parte e instrumento de gestão ambiental dos mamíferos aquáticos no projeto Piatam (Amazônia Central). Monografia apresentada para obtenção do título de Especialista em Gestão Ambiental. Universidade do Estado do Amazonas, Manaus-AM, 2008, 69 p.

Interações socioculturais da comunidade Tapiira com a fauna silvestre: relações de gênero e geração. Dissertação de Mestrado. Programa de Ciências do Ambiente e Sustentabilidade na Amazônia. Universidade Federal do Amazonas, 2011, 127 p. 
MORÁN, E. F. A ecologia humana das populações da Amazônia. Rio de Janeiro: Ed. Vozes Ltda., 1990, 367 p.

MOTTTA-MAUÉS, M. A. Pesca de homem/peixe de mulher: repensando gênero na literatura acadêmica sobre comunidades pesqueiras no Brasil. Etnográfica, v. III (2): 377-399, 1999.

PEREIRA, C. et. al. Análise da caça nas comunidades da área de atuação do Piatam. In: FRAXE, T. J. P.; PEREIIRA, H. S.; WITKOSKI, A. C. Comunidades ribeirinhas amazônicas: modos de vida e uso dos recursos naturais. Manaus: Edua, 2007.

PEZZUTI, J.; CHAVES, R. P., Etnografia e manejo de recursos naturais pelos índios Deni, Amazonas, Brasil. Acta Amazonica, v. 39 (1): 121-138, 2009.

SILVA, A. L. Animais medicinais: conhecimento e uso entre as populações ribeirinhas do rio Negro, Amazonas, Brasil. Bol. Mus. Par. Emílio Goeldi, Belém, v. 3, n. 3 , p. 343-357, set.-dez., 2008.

THOMAS, K. O homem e o mundo natural: mudança de atitude em relação às plantas e aos animais (1500-1800). São Paulo: Companhia das Letras, 2010. 